\title{
PerCursos
}

\section{O museu como ferramenta de reparação: apontamentos sobre memórias do trauma, museus e direitos humanos}

\begin{abstract}
Resumo
Assistimos desde o fim do século passado à consagração de toda uma série de patrimônios relacionados às memórias de catástrofes, guerras, genocídios, episódios de opressão, contextos de escravidão, tortura, sofrimentos, e toda sorte de situações traumáticas, violações de direitos e violências de Estado que, a partir das reivindicações de determinados grupos, assumem um valor simbólico e memorial. Sítios de consciência, museus para a paz, museus de memórias traumáticas, museus de direitos humanos, museus de memórias difíceis, memoriais; podemos encontrar na literatura uma série de nomenclaturas através das quais se procura identificar esse "novo" perfil de museus. Muitas dessas instituições são criadas a partir da perspectiva de um dever de memória. Geralmente por governos ou grupos de transição após o período em que se efetivou a situação de opressão ou violação dos direitos. O presente trabalho apresenta, por meio de revisão bibliográfica sobre a temática, o surgimento dessas instituições tendo como marco o período pós-Segunda Guerra. Em seguida, evidencia algumas das estratégias espaciais e museográficas comuns a elas e, por fim, traz uma reflexão sobre algumas das questões éticas envolvidas no uso dos museus como instrumentos de reparação.
\end{abstract}

Palavras-chave: Museus. Memória. Reparação. Direitos Humanos.

\author{
Felipe Eleutério Hoffman \\ Doutorando em Ciência da \\ Informação na Universidade \\ Federal de Minas Gerais - UFMG. \\ Professor da Universidade \\ Federal de Minas Gerais - UFMG. \\ Brasil \\ hoffmanfelipe@yahoo.com.br
}

\author{
Para citar este artigo: \\ HOFFMAN, Felipe Eleutério. O museu como ferramenta de reparação: apontamentos sobre \\ memórias do trauma, museus e direitos humanos. Revista PerCursos, Florianópolis, v. 20, n.42, p. 129 - \\ 158, jan./abr. 2019.
}

DOI: $10.5965 / 1984724620422019129$

http://dx.doi.org/10.5965/1984724620422019129 


\title{
The Museum as a tool for reparation: notes on trauma memory and human rights
}

\begin{abstract}
From the end of the last century we have witnessed the consecration of a whole series of patrimonies related to the memories of catastrophes, wars, genocides, episodes of oppression, contexts of slavery, torture, suffering and all sorts of traumatic situations, violations of rights and violence of State that, from the claims of certain groups, assume a symbolic and memorial value. Sites of Consciousness, Museums for Peace, Museums of Traumatic Memories, Human Rights Museums, Museums of Difficult Memories, Memorials, we can find in the literature a series of nomenclatures through which we try to identify this "new" profile of museums. Many of these institutions are created, from the perspective of a duty of memory. Generally by governments or transition groups after the period in which the situation of oppression or violation of rights has taken place. The present work presents the emergence of these institutions, having as a mark the period after the second great war, shows some of the spatial and museographic strategies common to them and finally brings a reflection on some of the ethical issues involved in the use of museums as instruments of reparation.
\end{abstract}

Keywords: Museums. Memory. Recovery. Human Rights. 


\section{Introdução}

Com a expansão do campo patrimonial'1, soma-se, à diversidade de memórias, uma multiplicidade de novas relações e valores atribuídos às categorias patrimoniais. Artístico, histórico, cultural, natural, identitário, simbólico - são diversas as adjetivações feitas à categoria do patrimônio. Comumente, monumentos, lugares e artefatos, ao serem percebidos como patrimônio, têm a si associados valores que remetem a um sinal “positivo”, tradições, saberes, práticas e objetos que se desejam preservar para as gerações futuras.

No entanto, assistimos desde o fim do século passado à consagração de toda uma série de patrimônios relacionados às memórias de catástrofes, guerras, genocídios, episódios de opressão, contextos de escravidão, tortura, sofrimentos, e toda sorte de situações traumáticas, violações de direitos e violências de Estado que, a partir das reivindicações de determinados grupos, assumem um valor simbólico e memorial. Por todo mundo, acontecimentos como o Holocausto, a Guerra Fria, atos de "terrorismo" global, as ditaduras nos países da América Latina, entre diversas outras situações, se tornam temáticas e questões abordadas por instituições museais. Observa-se uma crescente criação de museus consagrados a temas considerados de tratamento difícil, não só pelas especificidades das coleções e memórias que articulam, mas também devido às questões éticas envolvidas.

Sítios de consciência, museus para a paz, museus de memórias traumáticas, museus de direitos humanos, museus de memórias difíceis, memoriais - podemos encontrar na literatura uma série de nomenclaturas através das quais se procura identificar esse "novo" perfil de museus. Para além de lidar com temas e situações socialmente sensíveis, que envolvem algum episódio de violação de direitos e violências, essas instituições têm em comum a assunção de uma postura de instigar uma

\footnotetext{
${ }^{1}$ A demanda de diferentes grupos pela preservação dos testemunhos de sua história, somada à inclusão no conjunto dos objetos considerados como de interesse para preservação, dos testemunhos da era industrial, ocasiona uma expansão tipológica para o conceito de patrimônio. Tal expansão patrimonial faz com que museus e demais instituições de memória incluam objetos pertencentes a um passado cada vez mais próximo do presente. Resulta, nas palavras de Choay (2001, p. 209), numa espécie de "complexo de Noé", no qual se parece pretender abarcar a totalidade da realidade humana em uma arca patrimonial.
} 
transformação profunda na sociedade (CARTER, 2013; DUFFY, 1993). Convocam seus visitantes a se engajarem em ações de cidadania e inserem o público no centro de suas atividades.

São instituições que colocam em questão o papel social dos museus, ao se posicionar como agentes-chave em sua atuação junto à sociedade civil. A partir de suas ações, vão além das instâncias de representação das experiências humanas e assumem uma boa dose de "ativismo": posicionam-se como incentivadoras de mudanças sociais, encorajam reflexões morais sobre os deveres e direitos das pessoas enquanto cidadãos e deixam explícita uma atuação no sentido de objetivar mudanças nas formas de pensamento, nas mentalidades. Ao mesmo tempo, mobilizam as comunidades a tomar partido, a se engajar na ação e intervenção social.

Muitas dessas instituições são criadas a partir da perspectiva de um dever de memória, geralmente por governos ou grupos de transição, após o período em que se efetivou a situação de opressão ou violação dos direitos. O conceito de "dever de memória" mobiliza saberes diversos como a Filosofia, o Direito e a História. Relaciona-se na contemporaneidade a questões identitárias e às lutas por reconhecimento e reparação no que diz respeito à memória de acontecimentos sensíveis.

Segundo Guazzelli (2010), o termo tem sua origem no âmbito francês pós-Segunda Guerra com o objetivo de honrar a memória de franceses assassinados durante a ocupação alemã e destacava uma imagem de heroísmo e resistência, ou seja, um dever de lembrança e homenagem aos mortos. Com o passar dos anos, é ressignificado na década de 1970 a partir de sua interlocução com o contexto do Holocausto, quando assume um significado de justiça e, a partir dos testemunhos dos sobreviventes judeus, passa a produzir efeitos concretos nos domínios políticos e no campo das leis.

O conceito atravessa as décadas finais do século XX e chega ao contemporâneo em que, através de um efeito de projeção, o Holocausto se torna um modelo de ação para outros grupos que busquem afirmar suas memórias no espaço público e demandem por justiça na medida em que reconheçam um sofrimento imposto e a violação de direitos, sobretudo quando há participação do Estado nessas violações. Caso, por 
exemplo, dos torturados e dos familiares dos presos e desaparecidos políticos no contexto das ditaduras militares nos países da América latina.

Longe de ser um terreno pacífico, a ideia de um dever de memória é por vezes criticada². Na perspectiva de Ricoeur (2007), o dever de memória é antes de tudo um dever de não se esquecer, muitas vezes relacionado à reivindicação de uma história criminosa, feita pelas vítimas, que se justificaria por meio da ideia de se fazer justiça, relacionada aqui também à ideia de dívida. Percebe-se que o dever de memória é, nesta direção, uma memória obrigada e se relaciona diretamente às iniciativas memoriais que propõem ações de reparação moral às vítimas que sofreram algum tipo de violência de Estado, ou que foram alvo de violações dos direitos humanos. A percepção de uma dívida e, ao mesmo tempo, por não poder ser esquecida, de uma herança a ser transmitida.

Frequentemente, as Comissões da Verdade 3 criadas nos diversos países, após períodos de abuso de poder, recomendam, como forma de reparação simbólica às vítimas do abuso ou da violência de Estado, que se materialize um memorial. Embora possam estar ligadas a questões e lutas relacionadas a contextos regionais, esses memoriais, que em alguns casos assumem a forma de museus, permitem uma experiência compartilhada de identificação com os grupos e suas memórias. Em sua quase totalidade, a mensagem central defendida por essas instituições é a de que a lembrança desses acontecimentos funcione como catalisadora de um movimento que impeça a repetição de situações semelhantes. Nesses contextos, aparecem quase sempre atreladas ao conceito de justiça de transição.

\footnotetext{
${ }^{2}$ Ricoeur reconhece o campo da memória como uma arena de disputas; um dos objetivos perseguidos pelo autor é a ideia de uma política da "justa memória". Refere-se à questão moral de relatar o passado sem artifícios encobridores da "verdade". Por meio de um uso crítico da memória, intenciona um deslocamento da narrativa única, hegemônica, e possibilita o enlace e o entrelaçamento com outras narrativas. No entanto, para Ricoeur, se tornam inquietantes os excessos e as insuficiências de memória de um lado, e de esquecimento por outro. $O$ autor, então, expõe formas pelas quais o discurso da memória e do esquecimento se apresenta, por meio do que denomina como "usos e abusos da memória" e do esquecimento (Ricoeur, 2007).

${ }^{3}$ As Comissões da Verdade e Reconciliação, também chamadas de Comissões de Investigação, são umas das instâncias criadas, geralmente, após o fim de regimes de exceção; têm como finalidade investigar e avaliar as violações aos direitos humanos efetuadas durante esses regimes e, a partir de suas conclusões, decidir como repará-las. A experiência mais conhecida de Comissão da Verdade é sul-africana, criada naquele país para a investigação após o regime do Apartheid. Por sua notoriedade, foi tomada como modelo exportado para outros países do mundo (HUYSSEN, 2014, p. 14).
} 
Relativamente nova nas ciências sociais, a categoria de justiça de transição, também encontrada na literatura como justiça transicional, pode ser caracterizada como um conjunto de mecanismos para lidar com o legado de violência de Estados autoritários ou que sejam incapazes de preservar a integridade de seus cidadãos (ABRÃO; DIÈNE, 2015; REÁTEGUI, 2011). Dentro dos esforços para a construção de uma cultura para a paz que seja sustentável após períodos de conflitos, violações sistemáticas de direitos humanos e situações de violência em massa, a implantação de museus e memoriais objetiva atender, essencialmente, um duplo aspecto, pois, além de funcionarem como políticas de reparação individual e coletiva, moral e simbólica, possuem, ao mesmo tempo, uma dimensão clara de produção social de memória.

É a partir de algumas dessas chaves interpretativas que um número crescente de instituições adota as causas locais com relação aos direitos humanos como questão principal de sua missão institucional. Embora seja um fenômeno de grande expansão na contemporaneidade, com o crescimento da demanda por esses espaços no século $\mathrm{XXI}^{4}$, o uso dos museus como instrumentos de reparação ou marcos simbólicos dentro desses contextos de opressão e resistência não se trata de um acontecimento recente.

\section{Pioneirismos: pós-Segunda Guerra, Holocausto e alguns princípios} fundamentais

Podemos considerar como pioneiras as iniciativas realizadas no Japão, que na cidade de Osaka apresenta um Museu dos Direitos Humanos (Osaka Human Rights Museum), desde 1985, além dos dois museus implantados nas cidades de Hiroshima e Nagasaki inaugurados na década de 1990: o Museu Memorial da Paz de Hiroshima (Hiroshima Peace Memorial Museum) e o Museu da Bomba Atômica de Nagasaki (Nagasaki Atomic Bomb Museum).

\footnotetext{
${ }^{4}$ Um levantamento de alguns desses espaços em escala global pode ser visualizado no site da Coalizão Internacional dos Locais de Consciência, que conta hoje com mais de 200 instituições e iniciativas de memória. Disponível em: https://www.sitesofconscience.org/pt/members-2/. Acesso em: 20 de Jul de 2019.
} 
Também são precursoras as experiências relacionadas ao Holocausto: o Museu do Holocausto (United States Holocaust Memorial Museum), em Washington, e o Museu Judaico (Jüdisches Museum Berlin), em Berlim, inaugurados na década de 90 do século passado. Cabe destacar o pioneirismo dentro da temática do Holocausto do Museu Memorial Auschwitz-Birkenau, localizado na cidade de Oświęcim, na Polônia, cuja primeira exposição foi aberta ao público em 1947. A partir dessa data, o museu sofreu várias mudanças, até chegar à configuração que tem hoje.

Como visto, na perspectiva do "dever de memória", a rememoração do Holocausto, através de diferentes relações e projeções, tem atuado como um referencial. Nesse sentido, muitas das experiências museais que se desenvolvem ao redor do globo têm nos memoriais do Holocausto um referente fundamental. Portanto, a partir das experiências de "memorialização" do Holocausto são pensadas diversas estratégias por meio das quais as memórias de diferentes acontecimentos traumáticos, de situações e acontecimentos dolorosos e sofridos, podem ser conservadas, lembradas e comemoradas nos espaços urbanos.

Conforme o teórico da memória Andreas Huyssen, as razões para a dispersão e mobilidade global que as narrativas da memória do Holocausto alcançaram no contemporâneo se traduzem em quatro grandes fatores. O Holocausto foi, em primeiro lugar, umas das bases históricas da Convenção de Genebra de 1948, que tratava de genocídios e violações maciças dos direitos humanos. Em segundo lugar, o mesmo se constitui como a mais estudada das catástrofes humanas, o que resulta em uma profusão de trabalhos acadêmicos que oferecem modelos para as pesquisas sobre outros traumas históricos. Um terceiro ponto está relacionado às estratégias e práticas narrativas da literatura ficcional, documental e às representações artísticas e estéticas sobre o Holocausto, que influenciam as representações de outros traumas históricos. Por fim, é citado o alcance midiático das diversas imagens, produções cinematográficas e televisivas sobre o Holocausto, bem como as diferentes datas e eventos comemorativos, que passam a ser realizados não só em território alemão (HUYSSEN, 2014).

No entanto, cabe rememorar que a assimilação do tropo discursivo do Holocausto em contextos internacionais diversos, sobre diferentes maneiras, pode ser problemática. 
Sem o devido amadurecimento e a reflexão necessária, ao contrário de potencializar os discursos em torno das realidades locais, pode-se acabar produzindo amarras ao desenvolvimento de abordagens inovadoras 5 .

Ainda que pesem essas observações cautelares, alguns desses museus encontramse entre os locais mais visitados do mundo. Refletem uma dupla perspectiva: ao mesmo tempo em que oferecem um espaço físico e uma oportunidade para o luto, cicatrização e reflexão para as perdas decorridas do evento (efeito potencialmente significativo para os familiares, no que se refere às perdas humanas), constituem-se como locais em que memórias, por vezes legadas à clandestinidade, podem ascender ao espaço público de forma a garantir uma instância de preservação e compartilhamento. Revelam um entendimento da memória como instância de resistência e obstáculo à ocultação, uma das perspectivas fundamentais na ótica do sobrevivente (CASTRO, 2002).

A museóloga canadense Jennifer Carter, baseada nos escritos da pesquisadora americana Janet Marstine, ao abordar esse novo perfil de instituição museal propõe que três princípios fundamentais sejam observados. O primeiro diz respeito à questão da responsabilidade social (responsabilité sociale), que reflete a proposição de um museu mais inclusivo, que coloque em sua pauta modelos e métodos de participação democrática. Efetivamente propõe que o museu aceite a responsabilidade de operar como um lugar de ativismo (CARTER, 2013). Como segunda proposição, expõe a necessidade de transparência radical (La transparence radicale), que se refere ao fato dos museus se abrirem para discussão, seja para tratar de questões difíceis e controversas ou de questões cotidianas, principalmente com as comunidades diretamente relacionadas com as memórias enfocadas e com o patrimônio que referenciam. Esse princípio apresenta reflexos diretos, sobretudo nas atividades que envolvem o planejamento de exposições, fundamentalmente ligado à gestão dos conflitos de interesse (CARTER, 2013). Por fim, trata da aplicação do principio de cotutela do patrimônio (cotutelle du patrimoine), que parte da ideia de que os museus não são donos dos artefatos e das memórias que preservam e divulgam. Ao contrário, eles são confiados à instituição, o que

\footnotetext{
${ }^{5}$ A este respeito ver os estudos de HUYSSEN (2014) sobre a relação da memória do Holocausto com o contexto da ditadura militar na Argentina e também sua relação com a memória da violência colonialista nos países africanos (HUYSSEN, 2014.p.177-194).
} 
implica refletir em novas posturas com relação ao acesso e à difusão desse acervo e aos seus usos dentro das narrativas museais (CARTER, 2013).

Esses princípios são valores fundamentais que reverberam nas instituições museais como um todo, principalmente a partir do estabelecimento de um movimento por uma nova museologia a partir da segunda metade do século XX, que é, em essência, uma museologia socialmente engajada. Almeja-se a inclusão de um público diverso e plural no processo museológico e cria-se um espaço de diálogo e de debate cultural compartilhado, principalmente na percepção do museu como um espaço interdisciplinar.

\section{Articulações espaciais: entre novas arquiteturas e as edificações como}

\section{documentos}

Dentro da diversidade de instituições museais que surgem no contemporâneo e que apresentam como missão institucional trabalhar a memória de acontecimentos traumáticos, verificam-se diferentes instâncias e estratégias de articulação do espaço como suporte para as ações de rememoração. Da mesma forma, notam-se algumas similaridades de discursos e de escolhas conceituais que perpassam por alguns projetos. Essas instituições irão apresentar soluções arquitetônicas variadas, onde podemos observar tanto a construção de novos edifícios, quanto a adaptação de antigas edificações. O interessante é perceber que, em ambas as linguagens, a arquitetura tem um papel fundamental. Através dela, desenvolve-se uma estrutura de intertextualidade, na qual uma série de referências, histórias e narrativas são relacionadas e sobrepostas, como suporte para a construção semântica que se efetua a partir dos edifícios. A edificação se torna parte integrante e ativa da narrativa museal.

Nos edifícios de nova arquitetura, a linguagem utilizada permite o uso do projeto arquitetônico de maneira a construir um forte simbolismo: o intuito é causar impacto no público antes mesmo que este adentre o espaço museal. A escolha de materiais e formas passam a mensagem que a instituição deseja comunicar ao público. Pode-se constituir na tentativa de transmitir a experiência da violência do trauma histórico abordado: 
assimetrias, distorções, corredores e formas de deslocamento sempre em mutação, vazios, estruturas fragmentadas, rasgos e um sem número de outras estratégias que adentram o repertório arquitetônico de maneira a propor o engajamento do visitante. A edificação também pode expressar valores e ideias que se relacionam ao trauma através de características antinômicas, esboçando, por exemplo, uma mensagem de paz e tranquilidade, por oposição ao acontecimento de violência e agitação: superfícies claras, simetria, curvas harmônicas, fontes e espelhos d'água - que aparecem como elemento de purificação. Independente da escolha adotada, o que parece quase como impossível é uma relação de indiferença com sua intervenção no espaço.

O Museu Judaico de Berlim, projetado pelo arquiteto Daniel Libeskind, se constitui como caso paradigmático. A edificação pode até não conseguir fugir às críticas a uma monumentalização ou estetização da arquitetura, mas ainda assim se mostra arquiteturalmente ousada. Sua estrutura se baseia na relação entre linhas retas, e fragmentadas, despedaçadas, contorcidas, formando uma estrela de Davi retorcida. Soma-se, ainda, a presença de espaços vazios que cortam a estrutura e as janelas que permitem, a quem está no interior, uma visão fragmentada do ambiente externo, ao mesmo tempo em que produz efeitos de rasgos na superfície da edificação para um observador externo 6 .

O edifício é capaz de atingir o visitante simbólica e psicologicamente tendo, para alguns autores, a capacidade de expressar a memória do Holocausto de maneira intensa, mesmo sem todo o atual aparato museográfico montado na edificação (CHAMETZKY, 2008; HUYSSEN, 2000). O edifício se posiciona como a principal estrutura, atua diretamente na museografia e no discurso museal. Tanto que, após a inauguração da edificação, em 1999, o museu permaneceu ainda por dois anos completamente "vazio". O

\footnotetext{
${ }^{6}$ Diferentes leituras sobre a edificação podem ser feitas. Neste ensaio exponho as mais centrais para a discussão ora proposta. Algumas são corroboradas pela própria instituição, conforme o site institucional: "The building allows for many interpretations. For some people it brings to mind a broken Star of David; for others it is a bolt of lightning. Many people are left with a feeling of insecurity or disorientation." Para mais informações ver: https://www.jmberlin.de/en/libeskind-building. Acesso em: 20 de Jul de 2019.
} 
atual circuito de exposições foi montado em seu interior apenas no ano de 2001. Naquela época, a instituição já atraía um número considerável de visitantes?7.

Outro caso exemplar para tratarmos dos museus como instrumentos de reparação a partir de uma nova arquitetura é o Museu da Memória e dos Direitos Humanos (Museo de la Memoria y los Derechos Humanos), em Santiago. A instituição, inaugurada em 2010, aborda a memória do período de ditadura no Chile (1973-1990), em que o país foi governado pelo ditador Augusto Pinochet. O projeto arquitetônico foi executado por um escritório de São Paulo e assinam sua autoria os arquitetos Mario Figueroa, Lucas Fehr e Carlos Dias.

O edifício adota como princípio uma "arquitetura da transparência" (CARTER, 2013, p.53): uma grande caixa retangular suspensa, translúcida durante o dia e completamente transparente à noite. Tal configuração do espaço se traduz como metáfora de uma instituição que objetiva a reconciliação com o passado, ao se mostrar límpida, transparente em suas formas e em suas práticas, por oposição ao caráter obscuro das práticas de desaparição, torturas e assassinatos recorrentes no regime militar de Pinochet. A entrada do edifício se caracteriza por um pórtico amplo, convidativo, com o objetivo de se mostrar um lugar democrático, aberto. Porém, sua estrutura é levemente deslocada do corpo principal, em uma diagonal, de maneira a transgredir a hierarquia de certas arquiteturas museais.

Os dois casos citados são representativos de toda uma paisagem de novos museus que propõem, já na construção de uma edificação nova, um momento de reflexão sobre as memórias que serão trabalhadas nesses espaços. Existe, porém outra constelação de instituições que tem na adaptação de edificações preexistentes as proposições de seu conceito arquitetônico. Assim como nos prédios especialmente projetados para a função museal, tais edificações apresentam um forte simbolismo e têm papel seminal a desempenhar na museografia das instituições; no entanto, apresentam dimensões distintas.

\footnotetext{
7 Segundo levantamento realizado por CHAMETZKY (2008), de fevereiro de 1999 a agosto de 2000, quando o museu foi aberto sem objetos, a instituição recebeu mais de 340.000 visitantes. Nos primeiros cinco anos de suas exposições (2001-2005) o número de visitação ultrapassou os 3 milhões de visitantes.
} 
Como um dos legados mais atrozes dos períodos, episódios e acontecimentos de violações de direitos humanos por todo mundo, está a longa lista de torturados, mortos e desaparecidos. Os sobreviventes, ao relatarem suas memórias, fazem sempre referências aos espaços físicos onde essas violações foram cometidas. Passadas as conturbações e estabelecidas as condições políticas para se efetuar um trabalho sobre essas memórias, geralmente se constitui como tarefa de um governo de transição democrática, ou das Comissões da Verdade e Reconciliação criadas por todo o mundo, a identificação dos locais onde foram cometidas tais práticas nefastas. A identificação desses locais permite a revelação pública do circuito do horror ao qual eram submetidas as vítimas.

São espaços que podem ser conceituados como "lugares quentes" (Lieux chauds), na definição de Serge Barcellini, por sua relação direta com os episódios de violações de direitos e situações de opressão. Carregam em sua materialidade as marcas da experiência, o que permite que sejam apropriados com maior facilidade pelos atores e grupos sociais que reconhecem nesses espaços parte de suas trajetórias sociais (BARCELLINI, 2005).

É a partir da identificação com as memórias desses acontecimentos de caráter difícil que as antigas construções associadas aos locais de violência e violação de direitos humanos têm se transformado em lugares de memória. "A ruína não provocaria preservação se não fosse identificada como monumento" (CASTRO, 2002, p. 110). Ferramentas potencialmente poderosas, neste sentido, têm sido algumas metodologias empregadas a partir dos estudos de cultura material, principalmente através do que se convencionou chamar de Arqueologia da Repressão e da Resistência, e a metodologia da Arqueologia da Arquitetura (ZARANKIN; NIRO, 2008).

A Arqueologia da Arquitetura aborda o espaço construído como reflexo das ideologias, costumes e práticas de uma sociedade, a partir da análise, escavação e da aplicação de métodos dos estudos arqueológicos nas edificações, combinados com os registros existentes sobre as sucessivas ocupações dos edifícios em questão. Plantas, registros da história oficial, bem como os testemunhos dos sobreviventes e familiares são confrontados na produção de estudos e discursos que objetivam um maior entendimento desses acontecimentos. Esses estudos constituem-se em instrumentos valiosos para a 
construção de uma história negligenciada sobre as memórias do trauma. Permitem não só uma abordagem das funções e do uso do espaço como instrumento de repressão, mas também da percepção dos esquemas de "perversidade e o sadismo das pessoas e das ideologias que formaram parte deste sistema" (ZARANKIN; NIRO, 2008, p. 208).

Quase sempre, essas instituições enfrentam trajetórias complicadas para sua preservação. Tanto por um questionamento dos valores patrimoniais que lhes são atribuídos, por serem locais associados a memórias de sofrimento, quanto pela vontade política de promover um ocultamento, em alguns casos apagamento, da memória desses acontecimentos, que podem tocar em aspectos incômodos para certos grupos sociais (como no caso do apoio civil à implantação de regimes de opressão).

A controvérsia e o conflito de interpretações com a versão do sentido do passado imposta ou negociada pelos vencedores não necessariamente desaparecem uma vez construído o memorial, o museu, o monumento. A passagem do tempo histórico, político e cultural necessariamente implica novos processos de significação do passado, com novas interpretações. $\mathrm{E}$ então surgem revisões, mudanças de narrativas e novos conflitos [...]. (JELIN, 2002, p. 56-57, tradução nossa)

Mas cabe lembrar que não somente os locais onde ocorreram torturas ou violências, de maneira explícita ou clandestina, podem ser convertidos em instituições museais. Observa-se uma gama de instituições museológicas que também abordam a memória de acontecimentos traumáticos, mas a partir da preservação de locais onde ocorreram ações de resistência a essas violações de direitos humanos.

Ressalto que a musealização é apenas uma das formas de preservação associadas à proteção desses lugares. Não se advoga aqui um desejo de musealização integral de todos os bens relacionados à memória desses episódios. É necessário que, antes de tudo, uma sociedade saiba fazer a correta gestão de seus bens patrimoniais, dando voz aos diferentes grupos envolvidos e ponderando a "adequada" aplicação de diferentes instrumentos de preservação. O desenvolvimento de políticas da memória deve levar em conta a dinâmica de mudança e renovação presente nos espaços urbanos. 
Como exemplo desses museus que ocupam edificações com estreita relação com as memórias traumáticas e violações de direitos, podemos citar o caso dos diversos campos de concentração do regime nazista. Até o ano de 1945, data que marca o fim oficial do conflito, milhares de campos de concentração foram criados na Alemanha e nos países ocupados pelos exércitos germânicos, estabelecendo lugares de trabalhos forçados, espaços de transição e campos de extermínio. A maioria desses locais, ou o que restou deles, foram objeto de preservação memorial dos governos de diversos países no período pós-guerra. Alguns deles assumiram uma vocação museológica, com a constituição de coleções, atividades de pesquisa, preservação e difusão (SANTOS, 2014). Além dos campos de Auschwitz-Birkenau, já citados, são bastante conhecidos na Alemanha: o Museu e Memorial de Sachsenhausen e o Memorial do Campo de Concentração de Dachau.

O Espaço Memória e Direitos Humanos (Espacio Memoria y Derechos Humanos) localizado em Buenos Aires, se configura como um complexo de museus, arquivos históricos e centros culturais, que lidam com a memória do período da ditadura argentina (1966-1983). São diversas edificações convertidas em instituições de memória instaladas no lugar onde antes se situava a denominada ESMA, Escuela de Mecánica de la Armada, que durante o período do regime militar se caracterizou como um dos mais emblemáticos centros clandestinos de detenção, tortura e extermínio. Assim como essas edificações, outras construções têm sido identificadas como centros clandestinos de detenção (CCDs) em território argentino, parte delas convertidas em espaços de memória. Casos do Club Atlético, El Olimpo, Virrey Cevallos e Automotores Orletti, edificações que tiveram seus espaços internos preservados como testemunhos do que ali acontecia e que foram convertidas em símbolos do terrorismo de Estado. Atualmente, se realizam visitas guiadas a esses antigos CCDs, oferecidas por sobreviventes e familiares (ZARANKIN; SALERNO, 2015).

Ao serem utilizadas na implantação de instituições museais, as edificações identificadas como lugares de memória dos diferentes acontecimentos traumáticos, através de procedimentos arqueológicos e/ou técnicas museográficas podem ter seus 
espaços articulados no intuito de produzir ambientações, (re)criações dos espaços associados à memória de repressão e violação de direitos.

\title{
Museografia de imersão: estratégias e linguagens para a afetividade,
}

\section{empatia e alteridade}

Muitas dessas instituições optam por uma abordagem museográfica, que objetiva articular o espaço construído de maneira impactante, o que não necessariamente se articula por meio do espetacular. Estabelecem uma conexão direta com os aspectos afetivos do visitante. Essa capacidade dos museus é, por vezes, muito esquecida ou relegada a segundo plano, principalmente em detrimento de um fetichismo exagerado. No desenvolvimento dessa argumentação, recorro ao relato de um pesquisador do campo dos museus:

\begin{abstract}
Minha primeira visita a um museu aconteceu muitos anos atrás, quando, junto com meu pai, passei uma tarde no Museu Histórico Nacional, no Rio de Janeiro. Eu tinha, então, uns dez anos de idade, e lembro bem como me impressionaram as dimensões imponentes do prédio, as armas, as alfaias, as peças de mobiliário. Passadas algumas décadas, percebi que nunca tinha esquecido aquela "primeira vez": o Museu tinha então entrado em mim para não mais sair. É esse o aspecto afetivo de que falei: a capacidade do museu de despertar emoções - eu diria de guardar, mas sobretudo de mostrar sensações e sentimentos, pensamentos e sonhos, sob a forma de matéria - ainda que essa matéria seja tão sutil que não se consiga percebê-la. Os museus são uma espécie de pequena-imensa janela através da qual, pessoas no presente observam o universo na forma de lugares, tempos e culturas diferentes. O Museu aproxima pessoas, mesmo que essas pessoas não vivam no mesmo lugar, não falem a mesma língua e sequer estejam no mesmo tempo. Em minha opinião, é essa a maior qualidade do Museu, e nela reside sua capacidade de conexão de despertar emoções. Esse é o aspecto afetivo. (BITTENCOURT, 2009, p. 20)
\end{abstract}

É esse aspecto afetivo das instituições museais que desejo destacar. Muitos dos museus que lidam com memórias traumáticas, utilizam do espaço como maneira de despertar emoções e sentimentos. Uma espécie de museografia de imersão parece tomar 
forma nesses lugares, com o objetivo de conectar o visitante às experiências do trauma vivenciadas pelos sobreviventes, vítimas e familiares.

Nesse ponto, é necessário destacar que, ao mesmo tempo em que proliferam representações em diferentes modalidades estéticas e narrativas, em múltiplas formas de mídia, de forma a moldar os processos da memória e do esquecimento nos diferentes países e culturas, no que tange a esses acontecimentos, são reconhecidas as impossibilidades de uma representação total e a singularidade da experiência do sobrevivente:

Mas esta conciliação não se dá sem rupturas ou autoquestionamentos. Não que exista um limite técnico para se descrever um evento catastrófico: a questão é que, por um lado, esta descrição sempre será parcial, por outro, ela nunca poderá dar conta da experiência do sobrevivente. (SELIGMANN-SILVA, 2006, p. 210)

É significativo adentrar o espaço do Museu do Holocausto em Washington e se deparar com o portal onde lemos a inscrição "Arbeit Macht Frei” (em português, "o trabalho liberta"). A estrutura curva de metal e a sombra que ela projeta, sobre a sala, se traduz como discurso no espaço ${ }^{8}$.

Na mesma direção, no Museu Casa de Anne Frank, em Amsterdã, somos conduzidos pela narrativa museal a percorrer os cômodos da casa; em alguns deles, vemos recriações do ambiente da época. Somos confrontados, no ponto máximo da visita, com o "anexo secreto", onde se esconderam, entre os anos de 1942-1944, os oito clandestinos, para escapar da perseguição nazista. Embora haja uma maquete que demonstra a disposição anterior dos quartos, o anexo, que foi esvaziado por ordem do regime nazista quando os clandestinos foram presos, assim permanece. Vazio, por decisão institucional, simboliza o vazio deixado por milhões de pessoas que foram levadas e nunca mais retornaram.

\footnotetext{
8“"Arbeit Macht Frei" é a inscrição encontrada sobre o portão de entrada das áreas dos campos de concentração nazistas. Um ditado irônico, pois as pessoas ali confinadas só eram libertadas com a morte, em suas múltiplas faces - os trabalhos forçados e a exaustão, os maus tratos, a fome, as doenças, os enforcamentos, os fuzilamentos, as câmaras de gás (SANTOS, 2014, p. 201).
} 
Destaca-se também o trabalho executado no Museu do Apartheid, em Johanesburgo. As edificações e o espaço museográfico são articulados de forma a reproduzir os espaços das cidades da África do Sul durante os anos de forte segregação racial sofrida naquele regime. Já na entrada, recebe-se um ticket de admissão, que classifica os visitantes como brancos e não brancos; só podem-adentrar o Museu nas entradas específicas.

Nessa mesma direção, há diversas outras estratégias com forte apelo espacial e afetivo. As listas ou as inscrições dos nomes das vítimas das diferentes formas de violências, por meio de monumentos ou de estruturas no espaço museal, se traduzem como uma velha estratégia da memória, muito utilizada em referência a soldados e combatentes, em monumentos relacionados a guerras (MELENDI, 2006). Conforme Jeudy:

\begin{abstract}
A fim de conservá-los na memória e manter a lembrança da catástrofe, uma comunidade pode tomar a decisão de erigir um monumento, como se faz para os soldados mortos no campo de honra. O morto não pode ter morrido "por nada". [...] A presença deles invoca o mesmo reconhecimento coletivo de um sacrifício. A lembrança da vítima desconhecida é oferecida ao olhar da comunidade para que esta possa ter a esperança de modificar-se [...]. Não se trata apenas de lutar contra o esquecimento, mas de dar um sentido póstumo à memória do morto, um sentido que continue sempre suscetível de ser atualizado. (JEUDY, 2005, p. 57-58)
\end{abstract}

Portanto, é comum, nos locais que se utilizam dessa estratégia, a presença de cartas, objetos, flores, deixados, geralmente, por familiares próximos aos nomes da pessoa perdida. O museu se converte, neste instante, em lugar de luto não só para a memória de uma coletividade, mas também como lugar para um luto pessoal, familiar. $\mathrm{E}$ pode se conectar ao universo do visitante como espaço de contemplação, reflexão, oração.

A fotografia, neste sentido, atua como outro elemento de poderosa conexão. A reprodução fotográfica dos desaparecidos, torturados, prisioneiros, assassinados, quase sempre retirada de documentos oficiais, em preto e branco, quando utilizada no espaço 
museal, recria um procedimento de rememoração e protesto comum aos grupos sociais. A fotografia no espaço do museu se mostra como um referente de uso estratégico. Ao lembrar tempos e seres que já se foram, funciona ao mesmo tempo como prova irrefutável de sua existência.

As palavras, os textos, ao lado das fotografias, constituem-se como os nós de uma rede de afetos que contextualiza o luto dos vivos e se abre para o desejo de uma memória continuamente renovada. [...] A utilização da fotografia vernacular - carteira de identidade, álbum de casamento, de família, de férias - nos processos comemorativos das catástrofes contemporâneas vem apontando para uma apropriação comunitária da rememoração, antes delegada aos desígnios do poder. [...] a materialidade afetiva de um rosto que, a partir da fotografia, estabelece um diálogo com aquele que a olha, sinaliza o inesquecível do momento, a ingenuidade, a alegria ou a emoção dos rituais diários e, ao mesmo tempo, nos obriga a perceber que essa imagem está fora do seu lugar as páginas familiares do álbum - e que aponta em direção a um vazio que nos inclui. (MELENDI, 2006, p. 236-237)

É nessa ressonância que as novas tecnologias e formas de comunicação também se encontram no espaço museal, principalmente através da apresentação de testemunhos relacionados às memórias da repressão. Sempre encontramos nos museus que lidam com memórias da repressão e do trauma, em algum momento de sua distribuição espacial e em suas exposições, uma confrontação com os depoimentos, muitas vezes carregados de emoções, dos sobreviventes, familiares, enfim das pessoas diretamente afetadas pelas situações de opressão e violação de direitos. Seja através de áudio-guias, das telas de TVs nas exposições, ou ainda em sua forma mais potencializada, a presença física do sobrevivente que sofreu a situação de repressão como um mediador no espaço museal.

Os museus que lidam com a memória de episódios de violações de direitos, repressão, resistência, violência de Estado e traumas históricos costumam disponibilizar um vasto conteúdo para acesso online. Seus sites na internet assumem a forma de um amplo arquivo com informações e a disponibilização de documentos sobre os acontecimentos que referenciam, não obstante as duras batalhas para a liberação dos 
documentos sobre o período das violações de direitos ou violências de Estado. Muitos desses museus acabam abrigando os arquivos referenciais sobre os ocorridos, casos do Espaço da Memória e dos Direitos Humanos (Buenos Aires) e do Museu da Memória e dos Direitos Humanos (Santiago), assim como os relatórios e documentações gerados pela atuação das Comissões da Verdade e Reconciliação.

\section{Questões éticas: problemáticas e desafios}

Complemento a reflexão abordando algumas das problemáticas e desafios com que esses museus se deparam. Muitos deles com sérias implicações éticas para o presente e futuro dessas instituições museais.

A primeira questão diz respeito às narrativas museais. Ao utilizar de suas exposições, ações educativas e demais programações como fundamento para a construção de suas narrativas, um museu que lida com memórias de episódios de violações de direitos e conflitos deve, de antemão, reconhecer que a instituição apresenta a sua própria interpretação dos eventos históricos e da abordagem dos direitos em questão. Embora encerrem o potencial de trazer à tona a memória de grupos sociais historicamente marginalizados e de permitir a criação de um espaço privilegiado para a discussão da memória de acontecimentos sensíveis, é preciso reconhecer que a instituição museal lida com questões difíceis de representação em seus espaços. Necessário se faz deixar claros os critérios em que se baseiam. Qual a concepção de direitos humanos abordada pela instituição? Algumas comunidades e grupos apresentam aspectos religiosos e culturais como fundamentos para seus direitos. Ainda que não se apresentem como locais para uma história totalizante e, sim, como lugares para múltiplas histórias e memórias, o estabelecimento das narrativas museais pressupõe sempre o estabelecimento de escolhas. Conforme Meneses:

Apesar dessa ambiguidade e flexibilidade de escala entre o pessoal e o público, é verdade que os contextos institucionais típicos - em particular a exposição museológica - ressemantizam o objeto profundamente, 
depositando crostas de significados que se cristalizam em estratos privilegiados, em detrimento dos demais. (MENESES, 1998, p. 98)

Nesse sentido, o artefato, ao ser abarcado dentro da narrativa museal, acaba, por ocasião do discurso da instituição, sendo utilizado para passar uma determinada mensagem. Ainda que o visitante seja livre para interpretar e agir sobre a realidade abordada, as narrativas museais exercem um papel fundamental na maneira como o mesmo percebe e se engaja no espaço.

A forma como as memórias dos acontecimentos são abordadas pela instituição exerce um papel fundamental sobre o público, inclusa aqui a opção por uma postura de discordância com a mensagem que a instituição objetiva construir. Um museu, ao lidar com memórias de acontecimentos traumáticos e com valores relacionados aos direitos humanos, pode adotar uma postura de apaziguamento, comumente identificada na vertente dos chamados "museus para paz" (DUFFY, 1993, p. 4). Ou ainda uma postura ativa de engajamento social e posicionamento político, absorvendo as novas tendências, memórias e reivindicações dos grupos sociais, propondo o museu e suas exposições como obra aberta, em permanente construção (CARTER, 2013).

Como exemplo de museus que adotam uma postura de apaziguamento, se enquadra o Museu Memorial da Paz de Hiroshima:

(...) o museu de Hiroshima, local de peregrinação maciçamente frequentado por crianças, é objeto de sérias controvérsias quanto às modalidades de exposição pública das memórias de guerra. Os efeitos da bomba atômica parecem apresentados como consequências de um cataclismo, e essa ocultação de qualquer ressentimento em relação aos americanos é reforçada por uma invocação universal da paz. A própria lembrança da deflagração é representada pelos resíduos de objetos, que evocam insistentemente a desintegração do corpo (fragmentos do vestido de uma menininha, triciclo calcinado...). Mas a transmissão da mensagem proposta, mesmo que fundada na situação de guerra, orienta ainda assim o olhar do visitante na direção da constatação trágica de uma fatalidade do destino. (JEUDY, 2005, p. 59-60) 
Em outra perspectiva, a do posicionamento político, os diferentes museus e memoriais do Holocausto, por exemplo, têm atuado de maneira importante no sentido de deslocar a possessão judaica da memória e da narrativa do Holocausto. Através deles, não só a experiência judaica, mas também a memória da perseguição de diferentes grupos minoritários, como os ciganos, poloneses, homossexuais, dissidentes religiosos e políticos, tem se integrado ao espaço museal. Nessa direção, o museu se renova discursivamente. Desprende-se da prática de seguir uma "história oficial”, obtendo a autonomia necessária para se tornar um espaço provocador de reflexões. Algumas dessas instituições inserem o museu em um debate mais amplo e, ao incorporar as diferentes vozes presentes nas questões sociais, levam o debate sobre o Holocausto e os campos de concentração a se relacionar com uma análise da intolerância no contemporâneo. Caso, por exemplo, do Museu do Holocausto de Curitiba, que trabalha a perspectiva dos negros afro-germânicos, as teorias raciais e suas implicações para o debate em direitos humanos ${ }^{9}$, e do Museu do Holocausto de Washington, que busca promover um debate a respeito das relações sobre a memória do Holocausto e o ativismo gay no contemporâneo ${ }^{10}$.

O crescimento dos movimentos de extrema direita, por todo mundo, também é uma das temáticas abarcadas por essas instituições, reforçando os vínculos desta experiência com os discursos dos direitos humanos em todo globo (CASTRO, 2002). Nesse sentido, ao mesmo tempo em que se faz necessário incorporar as memórias dos diferentes grupos, algumas vezes, ainda que discordantes, torna-se ainda mais substancial que o museu esteja vigilante para não produzir ou contribuir com uma ideia de hierarquização das memórias. Pode-se advogar a favor das memórias e direitos que são ali abordados, no entanto, não ao preço de promover a subjugação das memórias concorrentes.

\footnotetext{
9 "Nossa Luta: a perseguição aos negros durante o Holocausto", é um material educativo sobre a perseguição nazista de afro-germânicos, com um panorama histórico e biografias de vítimas da Shoah. Ele foi lançado em 2017, como programação do mês da Consciência Negra. Mais informações podem ser obtidas em: http://www.museudoholocausto.org.br/material-para-educadores/. Acesso em: 20 de Jul de 2019.

10 O tema foi alvo de diversas palestras no espaço do museu e se objetiva o lançamento de um livro sobre a temática. Para mais informações ver: https://encyclopedia.ushmm.org/content/en/article/ persecution-ofhomosexuals-in-the-third-reich.
} 
O Museu Memorial do Campo de Concentração de Sachsenhausen, em Berlim, já foi objeto de contendas com relação ao estabelecimento de suas narrativas e às memórias que abordava. Após a libertação de sobreviventes do campo com o fim da guerra em 1945, entre os anos de 1945-1950, o campo de concentração foi utilizado por soviéticos como prisão onde foram encarcerados antigos membros do regime nazista, bem como outros presos políticos. Durante essa época, vários dos presos morreram devido às más condições do local. A esse período da ocupação da edificação, foi reservado um espaço importante dentro da narrativa museal, o que fez com que um grupo de sobreviventes do campo de concentração, durante o período do regime nazista, questionasse a pertinência de tal abordagem. Entre as alegações estava justamente o fato de que, ao tratar dessas memórias, o museu diminuía o potencial do campo de concentração como espaço de denúncia da memória do terror nazista (BORDAGE, 1993).

Outra questão que gostaria de destacar, que se liga de forma estreita com a construção das narrativas museais, diz respeito ao relacionamento dessas instituições com seus financiadores. Os museus, ao lidarem com questões ligadas às memórias traumáticas e aos direitos humanos, ao se assumirem como local para um posicionamento crítico e propositivo, podem se tornar instrumentos para alterar a opinião pública sobre um local, grupo, aspecto da memória coletiva, ou inclusive de políticas e ações implementadas pelos governos locais.

Esses museus estão realmente aptos a promover os direitos humanos, com suas portas abertas ao público, sendo que suas paredes são sustentadas pelo Estado? Um museu que depende do financiamento público e que é muitas vezes fundado por iniciativa estatal, está de fato capacitado a livre e abertamente criticar as ações e políticas do Estado, incluindo aquelas dos dias atuais? (CARTER; ORANGE, 2011).

O Museu do Genocídio Tuol Sleng (Tuol Sleng Genocide Museum), localizado em Phnom Penh, capital do Camboja, encontra-se instalado em antiga prisão do regime do Khmer Vermelho, que governou o país de 1975 a 1979. As torturas, assassinatos, estupros e mortes por má alimentação, executadas por esse regime contra a população cambojana, se encontram amplamente documentadas e denunciadas no Museu. O acervo da instituição foi utilizado no período posterior ao regime como principal fonte de provas, 
nos processos estabelecidos pelo tribunal conjunto formado pelas Nações Unidas e o governo real do Camboja, no julgamento dos perpetradores e nas reparações aos sobreviventes (CARTER, 2013).

Em outro sentido, a inauguração do Museu Canadense dos Direitos Humanos na cidade de Winnipeg, no ano de 2014, trouxe consigo uma série de críticas no que se refere ao trabalho da memória da população indígena do país. O fato de não estarem incluídas nas exposições do Museu as históricas políticas de opressão às etnias indígenas do país resultou em uma ampla discussão pública na sociedade canadense. O governo do país e as autoridades locais se mostram resilientes à incorporação das reivindicações dos grupos indígenas no espaço museal. Tal constatação coloca em xeque as capacidades da instituição como um museu que se compromete a promover o respeito aos direitos humanos, a partir da constatação clara da influência que o governo atual exerce, como o principal mantenedor da instituição, e da inabilidade da instituição em criticar as políticas governamentais (CHRISTENSEN, 2015). Embora não se possa dar o impasse como resolvido, nos meses finais do ano de 2018 , uma nova exposição, justamente a respeito da repressão histórica às comunidades indígenas, foi inaugurada. A curadora responsável, Karine Duhamel, trabalhou conjuntamente com lideranças das diferentes comunidades dos povos originários do país na construção da mostra, na tentativa de solucionar a questão ${ }^{11}$.

\section{Observações sobre o contexto brasileiro}

No contexto brasileiro temos ainda poucas instituições museais dedicadas à preservação de memórias ligadas a acontecimentos de repressão e resistência ou à promoção dos direitos humanos. Parte disto está ligado ao fato de que a maior experiência traumática brasileira dos últimos anos, o período da ditadura civil-militar que se deu no país, entre os anos de 1964-1985, apenas recentemente vem ganhando debates e discussões ampliadas. Muito se deve também à Lei da Anistia, promulgada em 1979, que

\footnotetext{
"A curadora publicou um relato da experiência em artigo publicado no site do Museu que pode ser acessado em: https://humanrights.ca/story/approaching-the-human-rights-stories-of-indigenous-peoples.
} 
se constitui como um passo importante a partir da possibilidade de retorno ao país ou ainda da retirada da clandestinidade, de centenas de ex-perseguidos políticos, mas que, por outro lado, provocou, nas palavras de Ricoeur, um "esquecimento comandado" (RICOEUR, 2007, p. 102). Tendo em vista que a interpretação dada à lei naquele momento foi a de que era um caminho de "mão dupla", assim, foram anistiados perseguidos e perseguidores. Ao controlar a transição política, os setores ligados às forças armadas não permitiram, num primeiro momento, que as instituições e a população brasileira, em geral, se confrontassem de maneira direta com o passado de arbitrariedades e abusos cometidos.

No entanto, apesar disso, os círculos de familiares de mortos e desaparecidos, organizações em defesa dos direitos humanos e alguns pesquisadores e grupos de pesquisa sempre promoveram instâncias e lutas para o reconhecimento das atrocidades do período. Apenas recentemente tivemos as condições e abertura política para promover uma discussão sobre a memória desse acontecimento. A Comissão Nacional da Verdade $(C N V)^{12}$, instituída em 2012, encerrou seus trabalhos no final de 2014 e os seus relatórios já se encontram disponíveis para consulta. Entre as atribuições da Comissão se encontrava "a identificação das estruturas, dos locais, das instituições e das circunstâncias relacionadas à prática de violações de direitos humanos" (BRASIL, 2011). Potencialmente, alguns destes locais podem se tornar lugares de memória, que tenham como objetivo preservar as memórias deste período.

Uma das mais conhecidas experiências de adaptação de antigos locais relacionados à ditadura civil-militar brasileira, para uma função museal, é o Memorial da Resistência na cidade de São Paulo. Sediado em parte do prédio que abrigou o Departamento Estadual de Ordem Política e Social - Deops/SP nos anos de 1939 a 1943, foi o primeiro centro de detenção, tortura e assassinatos no Brasil a ser tombado (1999) e posteriormente musealizado (2008). A instalação desse museu não ocorreu sem conflitos

\footnotetext{
${ }^{12}$ A Comissão Nacional da Verdade (CNV) foi criada pela Lei 12.528/2011 e instituída em 16 de maio de 2012. Tem por finalidade apurar graves violações de Direitos Humanos ocorridas no país entre os dias 18 de setembro de 1946 e 5 de outubro de 1988. Seu mandato se estendeu até o mês de dezembro de 2014, com a entrega dos relatórios finais da Comissão. Entre os focos principais da CNV estava a apuração dos casos de desaparecidos políticos, bem como a identificação dos lugares relativos às práticas de opressão do regime ditatorial. Mais informações em: http://www.cnv.gov.br/index.php.
} 
e tentativas do governo do Estado de São Paulo de impor políticas de esquecimento (SOUSA, 2014).

A edificação abrigava algumas celas onde se encontravam diversas inscrições de pessoas presas durante o regime militar. No entanto, tais inscrições foram apagadas numa das tentativas de revitalização urbana da região, com vistas a instalar no local um "Memorial da Liberdade". O projeto foi amplamente contestado, o que resultou em seu abandono. Diante das pressões políticas (especialmente do Fórum dos Ex-Presos e Perseguidos Políticos) contra o falseamento da história que era o "Memorial da Liberdade", em janeiro de 2009, o espaço foi inaugurado com nova proposta. Desta vez, como "Memorial da Resistência". Numa das estratégias museográficas utilizadas pela instituição, alguns ex-presos refizeram parte das inscrições nas paredes das celas, como maneira de marcar simbolicamente o espaço e (re)criar o local das celas como ambiente museográfico (SOUSA, 2014)

Nessa mesma direção, temos, na contemporaneidade, uma série de novos projetos sendo desenvolvidos nos espaços das cidades do país que têm como premissa trabalhar a memória de acontecimentos traumáticos e um engajamento com as lutas pelos direitos humanos, abordando não só a memória do golpe civil-militar¹3.

Embora se observe uma ampliação das reflexões em torno das memórias sobre acontecimentos traumáticos, principalmente a partir das manifestações e mobilizações da sociedade civil, com reflexos nas políticas públicas, essas mesmas manifestações dão indícios de que a criação de espaços para discussão dessa memória é urgente. A pluralidade de discursos presente nas manifestações deixa claro que as instâncias utilizadas até o momento se demonstram ineficazes na produção de efeitos duradouros sobre a memória coletiva. A criação de museus que tenham como missão trabalhar aspectos dessas memórias pode ser uma estratégia eficaz nesse sentido.

Com a recente (re)ascensão de uma onda conservadora por todo país, com reflexos diretos nas disputas políticas pelo poder, memórias sociais concorrentes entram

\footnotetext{
${ }^{13}$ Algumas destas iniciativas que foram mapeadas até o momento são: Memorial da Luta pela Justiça (São Paulo), Memorial da Anistia Política do Brasil (Belo Horizonte), Memorial dos Direitos Humanos - Casa da Liberdade (Belo Horizonte), Memorial da Liberdade e Democracia Presidente João Goulart (Brasília).
} 
novamente em conflito e invadem o espaço público e as redes sociais. Com a vitória recente de um candidato à presidência do país nas eleições de 2018 que abertamente se opõe à reivindicação das memórias das violações de direitos, pelas vítimas, sobreviventes, amigos e familiares, no que tange aos anos da ditadura no país, os diferentes projetos de museus e memoriais que se encontravam em gestação no território nacional correm sério risco de não implantação. A inauguração de projetos desta natureza, em muitos casos já travada pela crise político/financeira que aqui se desenrolava, apresenta grande probabilidade de ser completamente abortada. A negação das memórias do período, bem como seu questionamento já se encontram em andamento com o surgimento de narrativas concorrentes que propõem mudanças que atingem dos livros didáticos às ações diretas de reparação, como o trabalho da Comissão Nacional da Verdade e da Comissão de Anistia ${ }^{14}$.

\section{Considerações finais}

O presente trabalho se apresentou como um sobrevoo sobre a implementação de museus como instrumentos de reparação em situações que envolvem memórias de acontecimentos e episódios de violações de direitos humanos, situações de opressão e resistência, violência de Estado e traumas históricos. Objetivou-se apresentar algumas das especificidades dessas instituições no que tange aos diferentes contextos de violações de direitos, suas decisões arquitetônicas, narrativas museais e práticas museográficas, bem como evidenciar problemáticas e desafios éticos envolvidos.

Geralmente, tais lugares de memória surgem a partir de movimentos sociais e políticos. Instituem-se para evitar o esquecimento, através da ação do Estado, muitas vezes em resposta às reivindicações das comunidades que defendem esses lugares como seus. No entanto, não é rara a ocorrência de desvios nesses processos. A apropriação de

\footnotetext{
${ }^{14}$ Exemplos das ações abordadas no texto podem ser conferidas nos seguintes links: https://www1.folha.uol.com.br/educacao/2019/04/livros-didaticos-vao-negar-golpe-militar-e-ditadura-dizministro-da-educacao.shtml https://www1.folha.uol.com.br/poder/2019/03/nao-houve-ditadura-teve-uns-probleminhas-diz-bolsonarosobre-regime-militar-no-pais.shtml
} 
iniciativas exitosas e auto-organizadas pelo Estado, com o passar do tempo, por exemplo, pode ocasionar algumas mudanças significativas nos rumos e significados desses lugares.

Essas experiências nos permitem questionar até que ponto o aporte de recursos a essas instituições não é dependente de uma autorização do discurso institucional. Certos temas, principalmente ligados às memórias traumáticas, podem ser incômodos na promoção da paz ou coesão social, podendo afetar inclusive a imagem dos governos de um país no exterior. Sobre quais enquadramentos torna-se possível abordar uma narrativa de genocídios ou atos de tortura? A partir das instituições abordadas, vimos que tanto se encontra a postura de fornecer o acesso à informação e permitir um encontro livre dos diferentes grupos com essas memórias, quanto à construção de uma narrativa museal com vistas a estabelecer um discurso claro de reconciliação.

A partir desses apontamentos, observa-se que tanto agentes do Estado como os membros da sociedade civil se colocam, na construção de tais espaços, em um campo de disputas, de desejos e direito à memória, em que se torna crucial entender que a circulação dessas memórias pode ser tanto benéfica quanto destrutiva para as comunidades que as experienciaram em seus contextos específicos. Na medida em que operam a um só tempo como campos discursivos, centros de interpretação e arenas públicas, inserem-se na disputa entre o que deve ou não ser rememorado.

\section{Referências}

ABRÃO, Paulo; DIÈNE, Doudou. Préfácio. In: GABRIEL, Bix (Ed.). Fortalecimento da memória, da justiça e dos direitos humanos no Brasil e no Hemisfério Sul. Brasília: Comissão Brasileira de Anistia, 2015. p. 11-16.

BARCELLINI, Serge. L'intervention de l'Etat dans les musées des guerres contemporaines'. In: BOURSIER, Jean-Yves (Ed.). Musées de guerre et mémoriaux: politiques de la mémoire. Les Editions de la MSH, 2005. p. 35-48.

BITTENCOURT, José Neves. As coisas dentro da coisa: observações sobre museus, artefatos e coleções. In: AZEVEDO, Flávia Lemos Mota de, et al. Cidadania, memória e patrimônio: as dimensões do museu no cenário atual. Belo Horizonte: Crisálida, 2009. p. 17-31. 
BORDAGE, Roger. Sachsenhausen: a flawed museum. Museum International. [Museums of war and peace], n. 177, v. XLV, n. 1, p. 26-31, 1993.

BRASIL. Lei n. 12.528, de 18 de novembro de 2011. Cria a Comissão Nacional da Verdade no âmbito da Casa Civil da Presidência da República. Brasília, DF: Planalto [2011]. Disponível em: http://www.planalto.gov.br/ccivil_03/_ato2011-2014/2011/lei//12528.htm Acesso em: 08 fev 2019.

CARTER, Jennifer. L'éthique dans les musées, créateurs de sens: nouvelles frontières, nouveaux enjeux. Musées [Société des Musées Québecois (SMQ)], v.31, 2013, p. 46-55.

CARTER, Jennifer; ORANGE, Jennifer. The work of museums: the implications of a human rights museology. In: CONFERENCE OF THE FEDERATION OF INTERNATIONAL HUMAN RIGHTS MUSEUMS (FIHRM), 2., 2011. Annals [...] Liverpool, UK. October, 2011. Disponível em: http://www.fihrm.org/conference/ conference2011.html\#papers . Acesso em: 07 fev 2019.

CASTRO, Ana Lúcia Siaines de. Memórias clandestinas e sua museificação: uma prospecção sobre institucionalização e agregação informacional. Rio de Janeiro, 2002. 18of. Tese (Doutorado em Ciência da Informação) - Escola de Comunicação, Universidade Federal do Rio de Janeiro, 2002.

CHAMETZKY, Peter. Not what we expected: the Jewish museum Berlin in practice. Museum and society, University of Leicester, v.6, nov. 2008.

CHOAY, Françoise. A alegoria do patrimônio. São Paulo: Estação Liberdade: Editora UNESP, 2001.

CHRISTENSEN, Amber. Canadian museum for human rights: building a historical consciousness through omission. York University: Museums and Galleries. 2015. Disponível em: https://www.academia.edu/12306014/Canadian_Museum_for_ Human_Rights_building_a_historical_consciousness_through_omission. Acesso em: 08 fev. 2019.

DUFFY, Terence. The peace museum concept. Museum International: [Museums of war and peace], Cambridge, MA, n. 177, v. XLV, p. 4-8, 1993.

GUAZZELLI, Dante Guimaraens. O dever de memória e o historiador: uma análise de dois casos brasileiros. Mosaico, Rio de Janeiro, v. 2, n. 4, p. 46 - 68, out. 2010. Disponível em: http://bibliotecadigital.fgv.br/ojs/index.php/mosaico/article/view/ 62792. Acesso em: 02 Jul. 2019. doi: http://dx.doi.org/10.1266o/rm.v2n4.2010.62792. 
HUYSSEN, Andreas. Seduzidos pela memória: arquitetura, monumento, mídia. Rio de Janeiro: Aeroplano, 2000.

HUYSSEN, Andreas. Culturas do passado-presente: modernismos, artes visuais, políticas da memória. Rio de Janeiro: Contraponto, Museu de Arte do Rio, 2014.

JELIN, Elizabeth. Los trabajos de la memoria. Madrid: Siglo veintiuno, 2002.

JEUDY, Henry-Pierre. Espelho das cidades. Rio de Janeiro: Casa da Palavra, 2005.

MELENDI, Maria Angélica. Antimonumentos: estratégias da memória (e da arte) numa era de catástrofes. In: SELLIGMAN-SILVA, Márcio (Org.), Palavra e imagem: memória e escritura. Chapecó, SC: Argos, 2006. p.227-246.

MENESES, Ulpiano T. Bezerra de. Memória e cultura material: documentos pessoais no espaço público. Estudos Históricos, Rio de Janeiro, v.11, n. 21, p. 89-103, 1998.

REÁTEGUI, Félix (Ed.). Transitional Justice: handbook for Latin America. Brasília: Brazilian Amnesty Commission, 2011.

RICOEUR, Paul. A memória, a história, o esquecimento. Campinas, SP: Editora da Unicamp, 2007.

SANTOS, Carlos Alberto Ávila. Auschwitz e Birkenau: espaços de memória da indústria da morte. In: SEMINÁRIO INTERNACIONAL DE MEMÓRIA E PATRIMÔNIO. 8., 2014, Pelotas. Anais [lugares de memória] [...]. Pelotas: Ed. da UFPel, 2014. p. 201-206.

SELIGMANN-SILVA, Márcio. Escrituras da história e da memória. In: SELLIGMAN-SILVA, Márcio (Org.). Palavra e imagem: memória e escritura, Chapecó, SC: Argos, 2006. p. 205225.

SOUSA, Priscila Paula de. Memória, objetos e edifícios - uma análise arqueológica sobre o edifício que sediou o Deops/SP. Revista de Arqueologia Pública, Campinas: Unicamp, n. 10, p. 196-211, dez. de 2014.

ZARANKIN, Andrés; NIRO, Claudio. A materialização do sadismo: arqueologia da arquitetura dos Centros Clandestinos de Detenção da ditadura militar argentina (1976-83). In: FUNARI, P.P. A.; ZARANKIN, A.; REIS, J. A. dos. (Org.) Arqueologia da repressão e da resistência na América Latina na era das ditaduras (décadas de 1960-1980). São Paulo: Annablume; Fapesp, 2008. p.183-210. 
ZARANKIN, Andrés; SALERNO, Melisa. Reflexões sobre os espaços para a memória da ditadura em Buenos Aires. In: SOARES,I.V.P.;CUREAU, S. (Org.). Bens culturais e direitos humanos. São Paulo: Edições Sesc,2015. p.259-290.

Recebido em: 18/02/2019 Aprovado em: 10/07/2019

Universidade do Estado de Santa Catarina - UDESC Centro de Ciências Humanas e da Educação - FAED

Revista PerCursos Volume 20 - Número 42 - Ano 2019 revistapercursos@gmail.com 